\title{
QUANTIFICAÇÃO DE PRESSÕES CRÍTICAS PARA O CRESCIMENTO DAS PLANTAS ${ }^{(1)}$
}

\author{
S. IMHOFF ${ }^{(2)}$, A. PIRES DA SILVA(3), \\ M. DE S. DIAS J UNIOR ${ }^{(4)} \&$ C. A. TORMENA(5)
}

\begin{abstract}
RESUMO
A compactação, uma das principais causas de degradação dos solos agrícolas, tem sido avaliada por meio de diversos indicadores: (a) de qualidade estrutural do solo para o crescimento das plantas, como o intervalo hídrico ótimo (IHO), e (b) de capacidade de suporte do solo, como a pressão de preconsolidação $\left(\sigma_{p}\right)$. E ste trabal ho foi realizado com o objetivo não só de relacionar o I HO e a $\sigma_{p}$, mas também de determinar valores de pressões críticas (Pcr) que possam ser aplicados ao solo sem restringir o crescimento das plantas ou provocar a compactação adicional do solo. O estudo foi realizado com amostras de Podzólico Vermelho-Amarelo, cultivado com cana-de-açúcar, no município de Piracicaba (SP). Na camada superficial do solo, foram coletadas trinta e seis amostras com estrutura indeformada para a quanti ficação do IHO e da $\sigma_{p}$. A partir do I HO, foi obtido o valor de densidade do solo crítica (Dsc) para o crescimento das plantas. $A \sigma_{p}$ foi linearmente relacionada com a densidade e umidade do solo, permitindo a incorporação dos valores de Dsc e do IHO para a quantificação de Pcr. Os resultados indicaram que a Pcr diminuiu linearmente com o incremento da umidade, variando de $360 \mathrm{kPa}$ a $500 \mathrm{kPa}$ para a faixa de umidade de $\theta=0,18 \mathrm{~m}^{3} \mathrm{~m}^{-3}$ a $\theta=0,12 \mathrm{~m}^{3} \mathrm{~m}^{-3}$. O parâmetro proposto permitiu definir pressões máximas que podem ser aplicadas ao solo, para diferentes umidades, sem promover a degradação da qualidade estrutural do solo para o crescimento das plantas.
\end{abstract}

Termos de indexação: compactação do solo, pressão de preconsolidação, intervalo hídrico ótimo, pressões críticas.

(1) Parte da Tese de Doutorado do primeiro autor, apresentada à Escola Superior de Agricultura Luiz de Queiroz - ESALQ/USP. Recebido para publicação em fevereiro de 2000 e aprovado em setembro de 2000.

(2) Engenheiro-Agrônomo, PG do Dep. de Sol os e Nutrição de Plantas, Escola Superior de Agricultura Luiz de Queiroz - ESALQ/USP. Av. Pádua Dias 11, Caixa Postal 9, CEP 13418-900 Piracicaba (SP). Bolsista da CAPES. E-mail: scigiave@carpa.ciagri.usp.br

(3) Engenheiro-Agrônomo, Ph.D., Dep. de Sol os e Nutrição de Plantas, ESALQ/USP. E-mail: apisilva@carpa. ciagri.usp.br

(4) Engenheiro-Agrícola, Ph.D., Dep. de Ciência do Solo, Universidade Federal de Lavras - UFLA. Bolsista do CNPq. E- mail: msouzadj@ufla.br

(5) Engenheiro-Agrícola, Dr., Departamento de Agronomia, Universidade Estadual de Maringá - UEM. Av Colombo 579, CEP 87030121 Maringá (PR). E-mail:catormen@uem.br 


\title{
SUMMARY: QUANTIFYING CRITICAL PRESSURES FOR PLANT GROWTH
}

\begin{abstract}
Compaction is one of the main causes of degradation of agricultural soils and it has ben evaluated through several indicators of: (a) soil structural quality for crop growth, such as theleast limiting water range (LLWR), and (b) load support capacity of thesoil, i.e, the preconsolidation pressure $\left(\sigma_{\mathrm{p}}\right)$. This research was carried out with theobjectiveto relate the LLWR and the $\sigma_{\mathrm{p}}$, as well as to determinecritical pressures val ues that can beapplied to the soil without inducing restrictive conditions to plant growth as well as additional soil compaction. Thestudy was conducted with soil samples of a Red-Yellow Podzolic soil (UItisol) cultivated with sugarcanefrom Piracicaba, Stateof SãoPaulo (Brazil). Thirty six undisturbed soil samples weretaken at thesuperficial layer to quantify the $\sigma_{p}$ and theLLWR. Soil critical bulk density ( $\mathrm{Dbc}$ ) was obtained from the LLWR. The $\sigma_{\mathrm{p}}$ was a linear function of the water content and soil bulk density, allowing theincorporation of Dbc and LLWR for quantifying the Pcr. The results indicated that Pcr decreased linearly with soil water content, varying from $360 \mathrm{kPa}$ to $500 \mathrm{kPa}$ for the soil water range from $\theta=0,18 \mathrm{~m}^{3} \mathrm{~m}^{-3}$ to $\theta=0,12 \mathrm{~m}^{3} \mathrm{~m}^{-3}$. Theresults allowed to definevalues of maximum pressures that can be applied to the soil, for different water contents, without promoting degradation of soil structural quality for plant growth.
\end{abstract}

Index terms: soil compaction, preconsolidation pressure, least limiting water range, critical pressurevalues.

\section{INTRODUÇÃO}

A compactação influi nas propriedades e funções físicas, químicas e biológicas do solo (Hakansson et al., 1988), sendo uma das importantes causas da degradação dos solos agrícolas no mundo (Hakansson \& Voorhees, 1998).

Em solos compactados ocorre alteração da estrutura, da densidade do solo, da porosidadetotal, do tamanho e continuidade dos poros (Dexter, 1988; Horn \& Lebert, 1994). Decorrentedisso, omovimento e o armazenamento da água, ar e calor também podem ser alterados, tendo si do verificados aumentos nas perdas de nutrientes por volatilização e lixiviação(Hakansson \& Voorhees, 1998). A redução na capacidade de infiltração de água do solo, decorrente da compactação da camada superficial, pode resultar em aumento do escorrimento superficial e erosão (Kayombo \& Lal, 1994). A compactação dos solos também pode reduzir a eficiência de utilização de fertilizantes e herbicidas pelas culturas, em razão do menor desenvolvimento radicular das plantas, aumentando os custos de produção (Hakansson \& Voorhees, 1998).

O estado de compactação do solo tem sido aval iado por meio de diversos parâmetros físicos, tais como: densidade dosol o (Campbell, 1994), porosidade total, relação de vazios (Veenhof \& McBride, 1996), densidade relativa (Hakansson, 1990; Silva et al., 1997), resistência do solo à penetração das raízes (Silva et al., 1994) e pressão de preconsol idação (Dias J unior, 1994; McBride\& J oosse, 1996; Kondo \& Dias J unior, 1999a), entre outros.
A pressão de preconsolidação $\left(\sigma_{p}\right)$ tem sido utilizada como indicador da capacidade de carga dos solos parcialmente saturados, uma vez que a aplicação de cargas maiores que esse valor leva a uma compactação adicional do sol o (Lebert \& Horn, 1991; Dias J unior \& Pierce, 1996). Segundo Römkens \& Miller (1971), solos que apresentam valores el evados de pressão de preconsolidação têm maiores possibilidades de apresentar condições físicas restritivas ao crescimento das raízes das plantas.

O ambiente físico do solo ao redor das raízes é caracterizado pela aeração, temperatura, umidade e resistência mecânica, sendo todas essas propriedades físicas do solo modificadas, em grau variável, pela compactação do solo (Boone \& Veen, 1994). Gupta \& Allmaras (1987) definiram uma faixa deumi dadeacima da qual a compactaçãoéprejudicial ao desenvolvimento radicular com base em três critérios: estresse crítico, no qual os agregados sofrem disal hamento, aeração crítica ( $10 \%$ da porosidadetotal) e resistência crítica do solo à penetração radicular. Entretanto, esses autores indicaram a necessidade dedelimitar, deforma mais precisa, valores deestresse crítico para o crescimento das raízes.

O conceito do "Least Limiting Water Range" (LLWR) foi proposto por Letey (1985) e desenvolvido por Silva et al. (1994) como indicador da qualidade estrutural do sol o para o crescimento das raízes, visto que integra, num único parâmetro, os três fatores importantes associados ao desenvolvimento das plantas: aeração, umidadee resistência mecânica do solo. Pesquisas têm mostrado que o LLWR, traduzido comol ntervalo HídricoÓtimo (I HO) 
(Tormena et al., 1998), é alterado pelo grau de compactação do solo (Silva et al., 1994; Silva \& Kay, 1997a; Betz et al., 1998). Entretanto, há carência de estudos que relacionem o indicador de qualidade estrutural dosolopara ocrescimentodas plantas (IHO) e o indicador de capacidade de suporte do solo $\left(\sigma_{p}\right)$.

O objetivo destetrabal ho foi relacionar ol HO ea $\sigma_{p}$, e determinar valores de pressões críticas que podem ser aplicadas ao sol o sem provocar condições restritivas ao crescimento das plantas e, ou, induzir compactação adicional do solo.

\section{MATERIAL E MÉTODOS}

Este estudo foi realizado em um Podzólico Vermelho-Amarelo cultivado com cana-de-açúcar, localizado no município de Piracicaba (SP). O horizonte superficial deste solo apresenta $730 \mathrm{~g} \mathrm{~kg}^{-1}$ de areia, $80 \mathrm{~g} \mathrm{~kg}^{-1}$ de silte e $190 \mathrm{~g} \mathrm{~kg}^{-1}$ de argila.

No local, foram escolhidos 18 pontos de amostragem, aleatoriamente e entre as linhas de cana, de onde foram coletadas três amostras (uma deformada e duas indeformadas), totalizando 18 amostras com estrutura deformada e 36 amostras com estrutura indeformada. As amostras foram retiradas no centro da camada superficial do solo $(0,0-0,10 \mathrm{~m})$. Dototal deamostras indeformadas, 18 foram col etadas empregando anéis vol umétricos de 25,4 $\mathrm{mm}$ de altura por $64 \mathrm{~mm}$ de diâmetro, e as outras 18 amostras indeformadas foram retiradas utilizando anéis volumétricos de $50 \mathrm{~mm}$ de altura por $50 \mathrm{~mm}$ de diâmetro.

Nas amostras deformadas determinaram-se a granulometria (Gee \& Bauder, 1986) e a densidade das partículas (Dp) (Blake \& Hartge, 1986). Com o objetivo de simular um gradiente de umidade, as amostras com estrutura indeformada foram saturadas com água por 24 horas e separadas em seis grupos de três amostras, sendo cada grupo submetido a um dos seguintes potenciais mátricos $(\psi):-0,005,-0,01,-0,03,-0,07,-0,1$ e -1,5 MPa, em mesa detensão eem panelas de pressão de Richards, conforme Klute (1986).

Após atingir o equilíbrio nos referidos potenciais, as amostras de $25,4 \mathrm{~mm}$ de altura por $64 \mathrm{~mm}$ de diâmetro foram submetidas ao ensai o de compressão uniaxial (Dias J unior, 1994). Para este ensaio utilizou-se um consolidômetro da marca Boart Longyear. As pressões $(25,50,100,200,400,800$ e $1.600 \mathrm{kPa}$ ) foram aplicadas por meio de ar comprimido até obter $90 \%$ da deformação máxima (Taylor, 1948). As amostras foram submetidas à aplicação de pressões sucessivas, sem efetuar o descarregamento das pressões previamente aplicadas (Larson \& Gupta, 1980; Kondo \& Dias J unior, 1999a,b). Após a liberação da pressão, as amostras foram secas em estufa a $105-110^{\circ} \mathrm{C}$, por $24 \mathrm{~h}$, e determinada a matéria seca do solo.
A densidade do solo foi calculada a partir dos val ores dematéria seca do solo previamente medidos e dos valores de volume do sol o após cada carga, os quais foram recal culados a partir das medidas lidas no consol idômetro. Obteve-se a curva de compressão do solo; ou seja, um gráfico com o logaritmo da pressão aplicada no eixo das abscissas versus a densidade do solo no eixo das ordenadas (Dias) unior \& Pierce, 1996). O valor da pressão de preconsolidação $\left(\sigma_{p}\right)$ foi calculado para cada amostra, utilizando o método proposto por Dias J unior \& Pierce (1995).

Após atingir o equilíbrio, nas amostras de $50 \mathrm{~mm}$ de altura por $50 \mathrm{~mm}$ de diâmetro, foi medida a resistência do solo à penetração, utilizando um penetrômetro el etrônico com velocidade constante de penetração de $1 \mathrm{~cm} \mathrm{min-1} \mathrm{e} \mathrm{um} \mathrm{cone} \mathrm{com} \mathrm{diâmetro}$ de base de $4 \mathrm{~mm}$ e semi-ângulo de $30^{\circ}$. Esse penetrômetro é equipado com um atuador linear e célula de carga de $20 \mathrm{~kg}$ acoplada a um microcomputador para a aquisição dos dados (Tormena et al., 1998). No centro geométrico de cada amostra, na profundidade de 5 a $45 \mathrm{~mm}$, uma leitura de resistência foi obtida a cada $0,1 \mathrm{~mm}$, perfazendo um total de 400 leituras, as quais foram utilizadas para calcular a média da resistência do solo à penetração de cada amostra. Determinada a resistência à penetração, as amostras foram secas em estufa a $105-110^{\circ} \mathrm{C}$, por $24 \mathrm{~h}$, e determinada a densidade do solo de acordo com Blake \& Hartge (1986).

Os valores de umidade volumétrica $(\theta)$ e do potencial matricial $(\psi)$ foram ajustados, utilizando a função empregada por Ross et al. (1991):

$$
\theta=a \psi^{b}
$$

em que $\theta$ éa umidade volumétrica do solo $\left(\mathrm{cm}^{3} \mathrm{~cm}^{-3}\right)$, $\psi$ é o potencial mátrico (MPa) e a e b são os parâmetros ajustados.

Os dados de resistência à penetração (RP) foram ajustados em relação à umidade vol umétrica $(\theta)$ e à densidade do solo (Ds), utilizando o modelo nãolinear proposto por Busscher (1990):

$$
\mathrm{RP}=\mathrm{a} \theta^{\mathrm{b}} \mathrm{Ds} \mathrm{s}^{\mathrm{c}}
$$

ou alternativamente:

$$
\text { In } \mathrm{RP}=\ln \mathrm{a}+\mathrm{b} \ln \theta+\mathrm{c} \ln \mathrm{Ds}
$$

$\mathrm{Na}$ equação (3), RP é a resistência à penetração (MPa), $\theta$ é a umidade volumétrica $\left(\mathrm{m}^{3} \mathrm{~m}^{-3}\right)$, Ds é a densidade do solo $\left(\mathrm{Mg} \mathrm{m}^{-3}\right)$ e $\mathrm{a}, \mathrm{b}$ e c são os coeficientes do model o ajustados.

O Intervalo Hídrico Ótimo (I HO) foi calculado para cada Ds medida, seguindo o método proposto por Silva et al. (1994). Para o cálcul o do I HO, val ores críticos de umidade na capacidade de campo $\left(\theta_{\mathrm{CC}}\right)$ (Haise et al., 1955), ponto de murcha permanente $\left(\theta_{\text {PMP }}\right)$ (Richards \& Weaver, 1944), porosidade de 
aeraçãoigual a $10 \%\left(\theta_{\mathrm{PA}}\right)$ (Grable \& Siemer, 1968) e resistência do solo à penetração igual a $2 \mathrm{MPa}\left(\theta_{\mathrm{RP}}\right)$ (Taylor et al., 1966) foram determinados, para cada val or de densidade medida. Os val ores de $\theta_{\mathrm{Cc}}$ e $\theta_{\mathrm{PMP}}$ foram obtidos pela equação 1 , enquanto a $\theta_{R P}$ foi cal culada a partir do modelo ajustado de RP. O teor deágua que correspondea uma porosidade de aeração de $10 \%\left(\theta_{\mathrm{PA}}\right)$ foi determinado como $\theta_{\mathrm{PA}}=\theta_{\text {sat }}-0,1$, enquanto o teor de água na saturação $\left(\theta_{\text {sat }}\right)$ foi cal culado a partir da Ds e da densidade de partícula (Dp).

Nas análises estatísticas, utilizaram-se técnicas de regressão linear e não-linear por meio do programa estatístico SAS (SAS, 1991).

\section{RESULTADOSE DISCUSSÃO}

A regressão linear entre $\sigma_{p}$ e $\theta$ indicou que a $\sigma_{p}$ decresce significativamente com o aumento da umidade do solo, conforme o modelo abaixo (Equação 4),

$$
\sigma_{p}=755,39-2303,6 \theta\left(R^{2}=0,81 ; n=18\right)
$$

A umidade do sol o explicou $81 \%$ da variabilidade dos dados ( $F=68,37 ; p<0,001)$, demonstrando a influência dessa variável na capacidade de suporte de carga dos sol os. A diminuição da $\sigma_{\mathrm{p}}$ com o aumento da umidade do sol o foi observada por vários autores, embora alguns deles tenham determinado uma dependência linear (Reinert, 1990; Veenhof \& McBride, 1996) e outros uma relação exponencial (DiasJ unior, 1994; Kondo \& DiasJ unior, 1999a).

A regressãolinear múltipla, usandoo procedimento "stepwise" (SAS, 1991), demonstrou quea densidade inicial do solo $\left(D s_{i}\right)$ foi outra propriedade que influenciou a $\sigma_{\mathrm{p}}$. A incorporação dessa variável no model o el evou significativamente o $\mathrm{R}^{2}$ para o valor de 0,92 ( $F=90,43 ; p<0,0001)$, conformeindicado na equação 5 ,

$$
\begin{gathered}
\sigma_{p}=307,11-2502,59 \theta+296,48 D s_{i} \\
\left(R^{2}=0,92 ; n=18\right)
\end{gathered}
$$

Os coeficientes do modelo para as variáveis $\theta$ e $D s_{i}$ foram altamentesignificativos $\left(\theta: p<0,0001, D s_{i}\right.$ : $p<0,0003)$. A equação 5 indica quea $\sigma_{p}$ érel acionada negativamente com a umidade do solo e positivamente com a densidade inicial do solo.

A figura 1 mostra a variação da $\sigma_{p}$ com os val ores de $D s_{i}$ e de $\theta$. O solo apresenta baixa capacidade de suporte de carga quando úmido, enquanto a resistência à deformação aumenta com o secamento do solo. Sol os com textura grossei ra, como o estudado, podem ser mais facilmente deformados quando úmidos em razão de o filme de água ao redor das partículas de areia atuar como lubrificante, facilitando o rearranjamento das partículas do solo.
Com o secamento, ocorre aumento na capacidade de suporte de carga desses solos, considerando a dificuldade de deformar os grãos deareia, constituídos basicamente de quartzo (Larson et al., 1980).

A dependência da $\sigma_{p}$ da densidade inicial do solo foi mencionada por vários autores (Reinert, 1990; Veenhof \& McBride, 1996; Kondo \& Dias J unior, 1999b). O incremento na $D s_{i}$ leva ao aumento das forças de fricção e dos pontos de contato entre as partículas e, conseqüentemente, à sua menor capacidade de movimentação. Nessas condições, a maior dificuldade de deformação do solo ocasiona aumento da capacidade de suporte de carga do solo (Guérif, 1994).

A densidade do solo (Ds) tem sido utilizada como indicador do estado de compactação dos solos (Campbell, 1994), apesar de refletir tanto o efeito das práticas de manejo quanto as características do solo, como a textura (Silva et al., 1997). O valor de Ds associado com condições estruturais do solo restritivas para o crescimento radicular foi definido por Silva et al. (1994) como densidade do solo crítica (Dsc), correspondendo ao valor de Ds em que o I HO éigual a zero.

Comomostrado na figura 1 , a $\sigma_{\mathrm{p}}$ varia amplamente com a umidade e Ds, razão por que se torna necessário escolher um valor de Ds para a determinação de valores de $\sigma_{p}$, esperando que esse valor seja indicativo de condições restritivas ao desenvolvimento das plantas. A utilização do valor deDsc no cál cul o da $\sigma_{\mathrm{p}}$ permitirá definir a capacidade de suporte de carga do sol o, levando em consideração a qualidade estrutural do solo para o crescimento das plantas. Para determinar a Dsc, as relações entre os val ores de umi dade correspondentes à capacidade

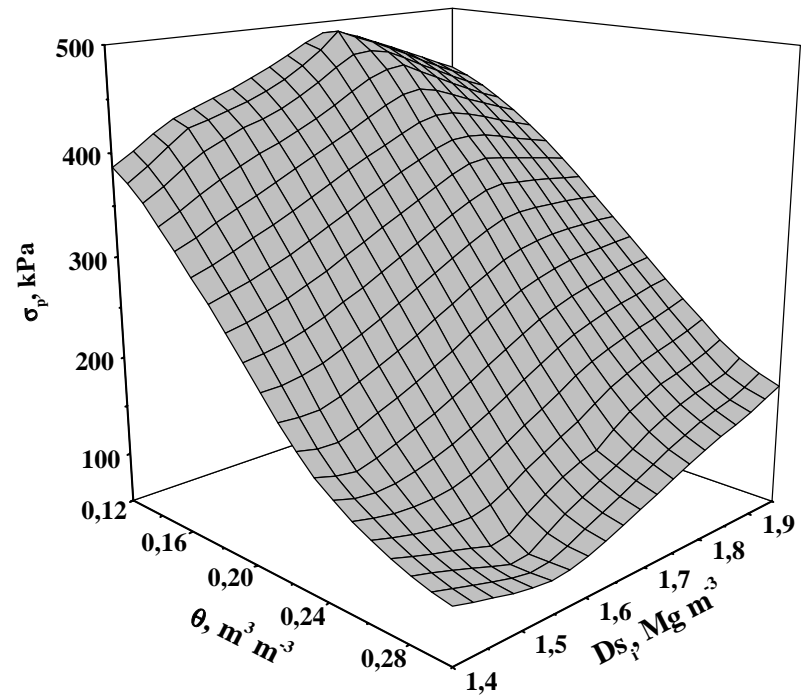

Figura 1. Variação dos valores da pressão de preconsolidação $\left(\sigma_{p}\right)$ com a umidade volumétrica $(\theta)$ e a densidade ínicial do solo $\left(D s_{i}\right)$. 
de campo $\left(\theta_{\mathrm{CC}}\right)$, ao ponto de murcha permanente $\left(\theta_{\mathrm{PMP}}\right)$, à porosidade de aeração $\left(\theta_{\mathrm{PA}}\right)$, à resistência do solo à penetração $\left(\theta_{\mathrm{RP}}\right)$ e Ds foram avaliadas. Os valores de umi dade considerados limites do I $\mathrm{HO}\left(\theta_{\mathrm{CC}}\right.$, $\left.\theta_{\mathrm{PMP}}, \theta_{\mathrm{RP}}, \theta_{\mathrm{PA}}\right)$, o IHO e a Dsc são mostrados na figura 2.

A resistência do solo à penetração foi alterada pela Ds eumidade do solo (Silva et al., 1994; Tormena et al., 1998). A Ds apresentou um coeficiente de variação (C.V. $=4 \%$ ) próximo ao determinado por Silva \& Kay (1997a) eTormena et al. (1998).

Os valores de umidade do solo relacionaram-se significativamente com o potencial mátrico ( $\left.F=110,80, p<0,0001, R^{2}=0,91\right)$; entretanto, a densidade do sol o não influenciou o ajuste dos dados no model o utilizado. Os coeficientes para o modelo ajustado (Ross et al., 1991) encontram-se na equação 6 ,

$$
\theta=0,305 \psi^{-0,116}
$$

utilizada para estimar a umidade volumétrica do solo nos potenciais de-0,01 MPa $\left(\theta_{C C}\right)$ e- $1,5 \mathrm{MPa}\left(\theta_{\mathrm{PMP}}\right)$, dados necessários para a determinação do I HO.

O model o da curva de RP ( $F=48,13, p<0,0001$, $\left.R^{2}=0,85\right)$, expresso em função das propriedades do sol o e segundo a equação (2), é o seguinte:

$$
\mathrm{RP}=0,0002 \theta^{-2,82} \mathrm{Ds}^{8,21}
$$

Os coeficientes do modelo mostram que a RP é negativamente relacionada com a umidade do solo ( $p<0,0001$ ) e positivamente relacionada com a Ds $(p<0,0002)$. Esse comportamento da resistência do solo é mencionado por vários autores, para solos e sistemas de manejo diferentes (Silva et al., 1994; Busscher et al., 1997; Tormena et al., 1998).

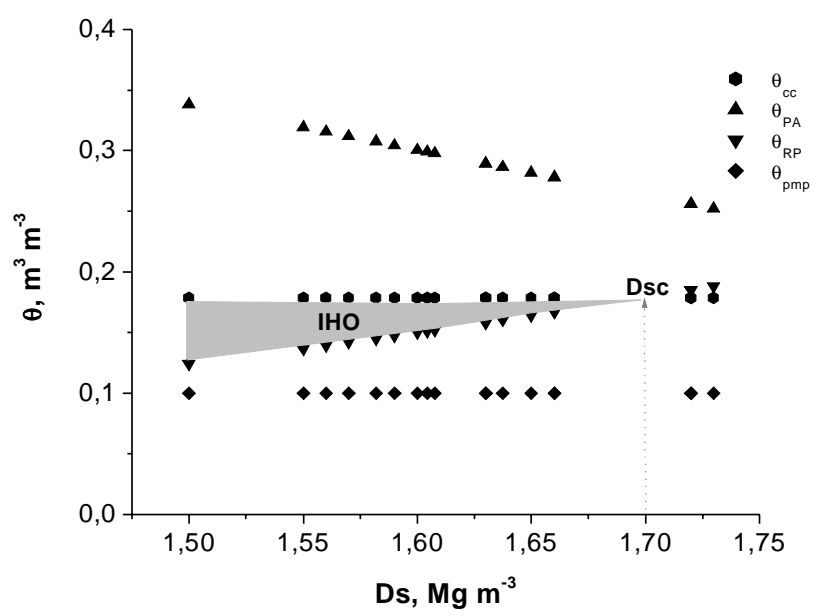

Figura 2. Variação da umidade volumétrica $(\theta)$ com a densidade do solo (Ds), para os limites críticos de capacidade de campo $\left(\theta_{c c}\right)$, ponto de murcha $\left(\theta_{\mathrm{PMP}}\right)$, porosidade de aeração $\left(\theta_{\mathrm{PA}}\right)$ e resistência do solo à penetração $\left(\theta_{\mathrm{RP}}\right)$. IHO = intervalo hídrico ótimo.
A umidade em quea RP atingiu oval or de $2 \mathrm{MPa}$, considerado limitante para o desenvolvimento radicular (Taylor et al., 1966; Weaich et al., 1992; Silva et al., 1994), foi determinada rearranjando a equação (7) e inserindo o val or de $2 \mathrm{MPa}$ para RP.

$A$ variação da Ds não influenciou a retenção de água pelo solo nos potenciais correspondentes à capacidade de campo $\left(\theta_{\mathrm{CC}}\right)$ e ponto de murcha permanente $\left(\theta_{\mathrm{PMP}}\right)$. Decorrente disso, não houve modificação da água disponível no solo $\left(\theta_{C \mathrm{C}}-\theta_{\mathrm{PMP}}\right)$ com o aumento da Ds. Comportamento similar foi encontrado por Silva et al . (1994) num sol o detextura arenosa.

A $\theta_{\mathrm{PA}}$ foi reduzida com o aumento da Ds. No entanto, a falta de oxigênio (porosidade menor que $10 \%)$ não se mostrou teoricamente restritiva ao crescimento radicular neste solo, visto que o limite de $\theta_{\mathrm{PA}}$ ocorreu sempre em valores de umidade maiores que $\theta_{c c}$, o que possivelmente pode ser atribuído à textura do solo.

Verificou-se que, com o aumento da Ds, o valor restritivo de resistência do solo $(R P=2 \mathrm{MPa})$ foi atingido com umidades no solo sucessivamente maiores. Esses resultados concordam com os obtidos por Silva et al. (1994), Betz et al. (1998) e Tormena et al. (1998). Esses autores observaram que a resistência do solo é o limite crítico que, com maior freqüência, reduz ol HO, sob condições de secamento do solo. A $\theta_{R P}$ foi o limite crítico inferior do IHO, superando a $\theta_{\text {PMP }}$ em toda faixa de densidades obti das nesteestudo, indicando redução da qualidade estrutural do solo. Esses resultados refletem, possivelmente, os efeitos do sistema intensivo de cultivo da gl eba das amostras.

O IHO foi definido, em todo o intervalo de Ds medidas, pela $\theta_{C C}$ (limite superior) e $\theta_{R P}$ (limite inferior) (Figura 2). Quanto menor a magnitude do IHO, maior o risco de expor as culturas a condições físicas do solo inadequadas por falta ou excesso de água (Silva \& Kay, 1997b). O IHO diminuiu com o aumento da densidade do solo e pode ser considerado reduzido (I HO variou entre 0 e $0,0545 \mathrm{~m}^{3} \mathrm{~m}^{-3}$ ), quando comparado aos val ores obtidos por Silva et al. (1994) para um solo canadense de textura semel hante ao estudado (IHO variou entre 0,0537 e 0,1326 $\mathrm{m}^{3} \mathrm{~m}^{-3}$ ).

O IHO demonstrou ser um indicador mais sensível que a água disponível para detectar alterações na qualidade física do solo com o incremento nos valores de Ds, concordando com os resultados de Silva et al. (1994), Betz et al. (1998) e Tormena et al. (1998).

O valor de Ds, em que ocorre a interseção das linhas relativas ao limite superior $\left(\theta_{C c}\right)$ e inferior $\left(\theta_{\mathrm{RP}}\right), \mathrm{IHO}=0$, é denominado densidade do solo crítica (Dsc), determinado como sendo igual a $1,70 \mathrm{M} \mathrm{g} \mathrm{m}^{-3}$. Valores de Ds maiores evidenciam condições altamente restritivas ao crescimento radicular. Esse val or foi utilizado na equação 5 para estimar a capacidade de suporte de carga do solo. 
Visto que a $\sigma_{\mathrm{p}}$ também varia com a umidade do solo, foi necessário definir valores de umidade de maior interesse. A faixa de umidade que incorpora as limitações para o crescimento das plantas relacionadas com a aeração, água disponível e resistência do solo à penetração ( $\theta$ variando entre 0,34 e $0,10 \mathrm{~m}^{3} \mathrm{~m}^{-3}$, Figura 2) foi escolhida para a realização dos cálculos. Os valores de $\sigma_{\mathrm{p}}$ para essa faixa de umidade e para $\mathrm{Dsc}=1,70 \mathrm{Mg} \mathrm{m}^{-3}$, estimados por meio da equação 5, são apresentados na figura 3.

A capaci dade de suporte de carga do sol o decresce rapidamente com o aumento da umidade no solo, variando entre 578 e $0 \mathrm{kPa}$, para os valores de umidade que correspondem ao ponto de murcha permanente e a $10 \%$ de aeração, respectivamente.

Considerando, na figura 3, a faixa de umidade correspondenteà máxima amplitude do I HO ( $\theta$ entre $0,18 \mathrm{e} 0,12 \mathrm{~m}^{3} \mathrm{~m}^{-3}$ ), identifica-se uma faixa de valores de $\sigma_{p}$, os quais representam pressões críticas para as plantas (PCr).

A pressão crítica para o crescimento das plantas $(\mathrm{Pcr})$ é definida, neste trabalho, como a pressão máxima que poderá ser aplicada ao solo sem provocar condições restritivas ao crescimento radicular (valores de Ds mai ores que Dsc) e sem promover deformação adicional do solo (valores de pressões maiores que $\sigma_{\mathrm{p}}$ ).

O intervalo de Pcr assim delimitado (máxima amplitude do IHO) varia, aproximadamente, entre 360 e $500 \mathrm{kPa}$ (Figura 3), os quais representam as pressões máxi mas que poderão ser aplicadas ao solo, sem provocar a sua degradação estrutural naquele intervalo de umidade (DiasJ unior et al., 1999). Essas

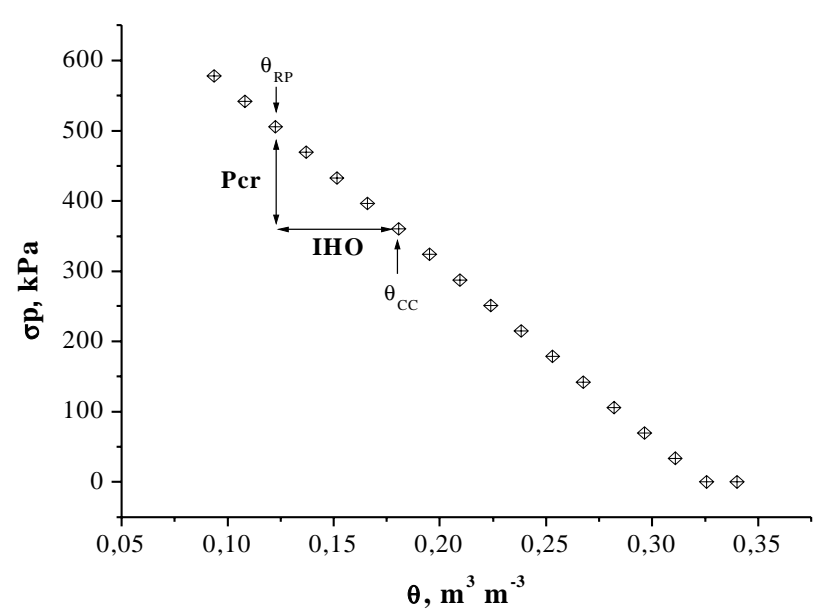

Figura 3. Variação da capacidade de suporte de carga do solo $\left(\sigma_{p}\right)$ com a umidade volumétrica $(\theta)$, para um valor de densidade do solo crítica igual a $1,70 \mathrm{Mg} \mathrm{m}^{-3}$. pressões são consideradas el evadas, tendo em vista a pressão aplicada ao solo pelos equipamentos motomecanizados tradicionais. Hakansson et al. (1988) já assinalavam val ores de pressões aplicadas aosol o quevariavam de 100 a $150 \mathrm{kPa}$, para tratores, e de 200 a 300 kPa, para colheitadeiras. A elevada capacidade de suporte de carga do sol o determinada neste estudo pode ser atribuída à textura e ao grau de compactação pretérita do mesmo.

Na figura 3, observa-se que os valores de umidade superiores a $0,18 \mathrm{~m}^{3} \mathrm{~m}^{-3}$ (capacidade de campo para o sol o estudado) levam à redução da capacidade de suporte de carga do solo. Para valores de umidade superiores a $0,18 \mathrm{~m} \mathrm{~m}^{-3}$, a aplicação de pressões superiores a 360 kPa leva à compactação adicional do solo e a condições restritivas ao desenvol vimento radicular ( $\theta_{\mathrm{CC}}=$ limite superior do I HO, Figura 2$)$.

Como indicado pela equação 5 , os val ores de $\mathrm{Pcr}$ dependem da umidade e do val or deDsc. A Dsc pode variar em função do valor de RP selecionado para a determinação do I HO. Pesquisas têm mostrado que, dependendo da espécie, as plantas diferem na sua capacidade de resposta a condições restritivas no ambiente radicular (Materechera et al., 1991). O I HO foi recalculado para valores de $\mathrm{RP}=1 \mathrm{MPa}$ e $\mathrm{RP}=3 \mathrm{MPa}$, os quais também têm sido mencionados na literatura como valores de RP críticos (Bengough \& Mullins, 1990). Os valores de Dsc obtidos foram: $D s c=1,56 \mathrm{Mg} \mathrm{m}^{-3}$, para $R P=1 \mathrm{MPa}$, e Dsc $=1,78 \mathrm{Mg} \mathrm{m}^{-3}$, para RP $=3 \mathrm{MPa}$. Os intervalos de $\mathrm{Pcr}$ recalculados foram de 316 a $461 \mathrm{kPa}$, para Dsc $=1,56 \mathrm{Mg} \mathrm{m}^{-3}$, e de 386 a $531 \mathrm{kPa}$, para e Dsc $=1,78 \mathrm{Mg} \mathrm{m}^{-3}$. A capacidade de suporte do solo continua sendo el evada, embora o valor de $\mathrm{Pcr}=316 \mathrm{kPa}$ possa ser mais facilmente superado por equipamentos motomecanizados modernos. Os resultados evidenciam a necessidade de cuidados adicionais para evitar a compactação adicional do sol o no caso de culturas mais sensíveis a RP.

A quantificação de $\mathrm{Pcr}$, como proposto, permite definir a pressão máxima que pode ser aplicada ao solo para diferentes umidades e valores de Dsc, auxiliando a seleção de sistemas de manejo sustentáveis. Neste contexto, a Pcr pode ser útil na escol ha de equipamentos agrícolas, bem como na definição do momento mais oportuno para a realização das atividades de preparo do solo e, ou, tráfego da maquinaria agrícola, principalmente em áreas irrigadas mecanizadas, nas quais a umidade é mantida dentro da faixa menos limitante determinada peloIHO.

O valor de Pcr pode vir a ser um indicador útil para prevenir a degradação da qualidade física dos solos, visto que reúne a informação oferecida pelo indicador de qualidade estrutural do solo para o crescimento das plantas (IHO) e pelo indicador de capacidade de suporte de carga dos solos $\left(\sigma_{p}\right)$. Mais pesquisas são requeridas nessa área de estudo para diferentes condições de clima, manejo e solos. 


\section{CONCLUSÕES}

1. A informação do I HO e da $\sigma_{\mathrm{p}}$ reunidas permite definir um novo indicador, a pressão crítica para o crescimento das plantas.

2. A Pcr é um indicador da pressão máxima que pode ser aplicada sem promover deterioração da qualidadefísica dosol o para ocrescimento das plantas.

\section{LITERATURA CITADA}

BENGHOUGH, A.G. \& MULLINS, C.E. Mechanical impedance to root growth: a review of experimental techniques and root growth responses. J. Soil Sci., 41:341-358,1990

BETZ, C.L.; ALLMARAS, R.R.; COPELAND, S.M. \& RANDALL, G.W. Least limiting water range: traffic and long-term tillage influences in a webster soil. Soil Sci. Soc. Am. J., 62:1384-1393, 1998.

BLAKE, G.R. \& HARTGE, K.H. Bulk density. In: KLUTE, A., ed. Methods of soil analysis: physical and mineralogical methods. 2.ed. Madison, American Society of Agronomy, 1986. p.363-375.

BOONE, F.R. \& VEEN, B.W. Mechanisms of crop responses to soil compaction. In: SOANE, B.D. \& van OUWERKERK, C., eds. Soil compaction in crop production. Amsterdam, Elsevier, 1994. p.237-264.

BUSSCHER, W.J . Adjustment of flat-tipped penetrometer resistance data to a common water content. Am. Soc. Agric. Eng., 3:519-524, 1990.

BUSSCHER, W.J .; BAUER, P.J .; CAMP, C.R. \& SOJ KA, R.E. Correction of cone index for soil water content differences in a coastal plain soil. Soil Till. Res., 43:205-217, 1997.

CAMPBELL, D.J . Determination and use of soil bulk density in relation to soil compaction. In: SOANE, B.D. \& van OUWERKERK, C., eds. Soil compaction in crop production. Amsterdam, Elsevier, 1994. p.113-139.

DEXTER, A.R. Advances in characterization of soil structure. Soil Tillage Res., 11:199-238, 1988.

DIAS J UNIOR, M.S. Compression of three soils under long-term tillage wheel traffic. East Lansing, Michigan State University, 1994. 114p. (Tese de Doutorado)

DIAS J UNIOR, M.S. \& PIERCE, F.J . A simple procedure for estimating preconsolidation pressurefrom soil compression curves. Soil Technol., 8:139-151, 1995.

DIAS J UNIOR, M.S. \& PIERCE, F.J . O processo de compactação do solo esua modelagem. R. Bras. Ci. Solo, 20:175-182, 1996.

DIAS J UNIOR, M.S.; FERREIRA, M.M.; FONSECA, S.; SILVA, A.R. \& FERREIRA, D.F. Avaliação quantitativa da sustentabilidade estrutural dos solos em sistemas florestais na região de Aracruz-ES. R. Árv., 23:371-380, 1999.

GEE, G.W. \& BAUDER, J .W. Particle-size analysis. In: KLUTE, A., ed. Methods of soil analysis: physical and mineralogical methods. 2.ed. Madison, American Society of Agronomy, 1986. p.383-411.
GRABLE, A.R. \& SIEMER, E.G. Effects of bulk density, aggregate size and soil water suction on oxygen diffusion, redox potential and elongation of corn roots. Soil Sci. Soc. Am. Proc., 32:180-186, 1968.

GUÉRIF, J . Effects of compaction on soil strength parameters. In: SOANE, B.D. \& van OUWERKERK, C., eds. Soil compaction in crop production. Amsterdam, Elsevier, 1994. p.191-214.

GUPTA, S.C. \& ALLMARAS, R.R. Models to assess the susceptibility of soils to excessive compaction. Adv. Soil Sci., 6:65-100, 1987.

HAISE, H.R.; HAAS, H.J . \& J ENSEN, L.R. Soil moisture studies of some Great Plain soils: II. Field capacity as related to 1/3-atmosphere percentage and "minimum point"as related to 15- and 26-atmosphere percentages. Soil Sci. Soc, Am. Proc., 34:20-25, 1955.

HAKANSSON, I. A method for characterizing the state of compactness of the plough layer. Soil Till. Res., 16:105-120, 1990.

HAKANSSON, I.; VOORHEES, W.B. \& RILEY, H. Vehicle and wheel factors influencing soil compaction and crop response in different traffic regimes. Soil Till. Res., 11:239-282, 1988.

HAKANSSON, I. \& VOORHEES, W.B. Soil compaction. In: LAL, R.; BLUM, W.H.; VALENTINE, C. \& STEWARD, B.A., eds. Methods for assessment of soil degradation. Advances in soil science. Boca Raton, CRS Press, 1998. p.167-179.

HORN, R. \& LEBERT, M. Soil compactability and compressibility. In: SOANE, B.D. \& van OUWERKERK, C., eds. Soil compaction in crop production. Amsterdam, Elsevier, 1994. p.45-69.

KAYOMBO, B. \& LAL, R. Responses of tropical crops to soil compaction. In: SOANE, B.D. \& van OUWERKERK, C., eds. Soil compaction in crop production. Amsterdam, Elsevier, 1994. p.287-316.

KLUTE, A. Water retention: laboratory methods. In: KLUTE, A., ed. Methods of soil analysis: physical and mineralogical methods. 2.ed. Madison, American Society of Agronomy, 1986. p.635-660.

KONDO, M.K. \& DIAS J UNIOR, M.S. Efeito do manejo e da umidade no comportamento compressivo detrês Latossolos. R. Bras. Ci. Solo, 23:497-506, 1999a.

KONDO, M.K. \& DIAS J UNIOR, M.S. Estimativa do efeito do uso e da umidade do sol o sobre a compactação adicional de três Latossolos. R. Bras. Ci. Solo, 23:773-782, 1999b.

LARSON, W.E. \& GUPTA, S.C. Estimating critical stress in unsaturated soils from changes in pore water pressure during confined compression. Soil Sci. Soc. Am. J ., 44:1127$1132,1980$.

LARSON, W.E.; GUPTA, S.C. \& USECHE, R.A. Compression of agricultural soils from eight soil orders. Soil Sci. Soc. Am. J ., 44:450-457, 1980.

LEBERT, M. \& HORN, R. A method to predict the mechanical strength of agricultural soils. Soil Till. Res., 19:275-286, 1991.

LETEY, J . Relationship between soil physical properties and crop production. Adv. Soil Sci., 1:277-294, 1985. 
MATERECHERA, S.A.; DEXTER, A.R. \& ALSTON, A.M. Penetration of very strong soils by seedling roots of different plant species. Plant Soil, 135:31-41, 1991.

MCBRIDE, R.A. \& J OOSSE, P.J. Overconsolidation in agricultural soils: II. Pedotransfer functions for estimating preconsoli-dation stress. Soil Sci. Soc. Am. J ., 60:373-380, 1996.

REINERT, D.J. Soil structural form and stability inducted by tillage in a typic Hapludalf. East Lansing, Michigan State University, 1990. 128p. (Tese de Doutorado)

RICHARDS, L.A. \& WEAVER, L.R. Fifteen atmosphere percentage as related to the permanent wilting point. Soil Sci., 56:331-339, 1944.

RÖMKENS, M.K. \& MILLER, R.D. Predicting root size and frequency from one-dimensional consolidation data- $A$ mathematical model. Plant Soil, 35:237-248, 1971.

ROSS, P.J .; WILLIANS, J . \& BRISTOW, K.L. Equations for extending water-retention curves to drynees. Soil Sci. Soc. Am. J ., 55:923-927, 1991.

SILVA, A.P.; KAY, B.D. \& PERFECT, E. Characterization of the least limiting water range. Soil Sci. Soc. Am. J ., 58:17751781, 1994.

SILVA, A.P. \& KAY, B.D. Estimating the least limiting water range of soil from properties and management. Soil Sci. Soc. Am. J ., 61:877-883, 1997a.
SILVA, A.P. \& KAY, B.D. Effect of soil water content variation on the least limiting water range. Soil Sci. Soc. Am. J ., 61:884888, 1997b.

SILVA, A.P.; KAY, B.D. \& PERFECT, E. Management versus inherent soil properties effects on bulk density and relative compaction. Soil Till. Res., 44:81-93, 1997.

SAS INSTITUTE. SAS/STAT procedure guide for personal computers. 5ed. Cary, NC. 1991.

TAYLOR, D.W. Fundamentals of soil mechanics. New York, J ohn Wiley \& Sons, 1948. 770p.

TAYLOR, H.M.; ROBERSON, G.M. \& PARKER J R., J J. . Soil strength-root penetration relations to medium to coarsetextured soil materials. Soil Sci., 102:18-22, 1966.

TORMENA, C.A.; SILVA, A.P. \& LIBARDI, P.L. Caracterização do intervalo hídrico ótimo de um Latossolo Roxo sob plantio direto. R. Bras. Ci. Solo, 22:573-581, 1998.

VEENHOF, D.W. \& MCBRIDE, R.A. Overconsolidation in agricultural soils: I. Compression and consolidation behavior of remolded and structured soils. Soil Sci. Soc. Am. J ., 60:362-373, 1996.

WEAICH, K.; CASS, A. \& BRISTOW, K.L. Use of a penetration resistance characteristic to predict soil strenght development during drying. Soil Till. Res., 25:149-166, 1992. 